\title{
Hypothalamic-pituitary-adrenal axis suppression in asthma: A glucocorticoid receptor polymorphism may protect
}

\author{
Wisdom Akurugu ${ }^{1}$, Carel van Heerden ${ }^{2}$, Nicola Mulder ${ }^{1}$, and Ekkehard Zöllner ${ }^{2}$ \\ ${ }^{1}$ University of Cape Town Faculty of Health Sciences \\ ${ }^{2}$ Stellenbosch University
}

May 19, 2020

\begin{abstract}
Background: Asthmatic children on corticosteroids can develop hypothalamic-pituitary-adrenal axis suppression (HPAS). Single nucleotide polymorphisms (SNPs) rs242941 and rs1876828 of the corticotrophin-releasing hormone receptor 1 (CRHR1) gene were associated with lower stimulated cortisol (F) levels, whereas rs41423247 of the glucocorticoid receptor (NR3C1) gene was associated with higher basal F levels. The objective of the current study was to confirm whether these three SNPs are associated with HPAS in asthmatic children. Methods: DNA was extracted from saliva obtained from 95 asthmatic children, who had previously undergone basal F and metyrapone testing. Thirty-six children were classified as suppressed. Non-suppressed children were sub-classified according to their post-metyrapone ACTH (PMTP ACTH) level into a middle (106-319 pg/ml) and a high $(>319 \mathrm{pg} / \mathrm{ml}$ ) ACTH response group. TaqManß polymerase chain reaction assays were utilized. Results: Only rs41423247 was inversely associated with HPAS (OR $=0.27$ [95\% CI 0.06-0.90]). Its GC genotype was inversely associated with HPAS (log odds $=-1.28, \mathrm{p}=0.021)$. [?]PMTP ACTH was associated with CC (effect size $=10.85, \mathrm{p}=0.005)$ and GC genotypes (effect size $=4.06, \mathrm{p}=0.023)$. The $\mathrm{C}$ allele is inherited as a dominant trait (effect size $=-1.31(95 \% \mathrm{CI}-2.39--0.33 ; \mathrm{p}=0.012)$. In the high ACTH response group, both genotypes affected the PMTP ACTH (effect sizes 1.41 and 15.46; p-values 0.023 and < 2x10-26 for GC and CC respectively). Conclusions: The C allele of rs41423247 was found to be protective against HPAS. CC genotype is associated with the highest PMTP ACTH response.
\end{abstract}

Hypothalamic-pituitary-adrenal axis suppression in asthma: A glucocorticoid receptor polymorphism may protect

Wisdom Alemya Akurugu*1)

CarelJacobusvan Heerden ${ }^{2)}$

Nicola Mulder ${ }^{1)}$

Ekkehard Werner Zöllner*3)

* WAA and EWZ should be considered joint first author

Institutional affiliations

1) Computational Biology, Department of Integrative Biomedical Sciences, University of Cape Town, Cape Town, South Africa

${ }^{2)}$ Central Analytical Facility, Stellenbosch University, Stellenbosch, South Africa

3) Paediatric Endocrine \& Diabetes Unit, Department of Paediatics and Child Health, Stellenbosch University, Cape Town, South Africa

Running title : HPAS, GC receptor polymorphism in asthma 


\section{Author responsible for correspondence}

EW Zöllner

Faculty of Health Sciences

Department of Paediatrics and Child Health

Stellenbosch University

PO Box 241

Cape Town

8000

South Africa

Word count : 2480

Word count abstract: 250

Title character count : 99

No of tables: 5

No of figures: 1

Conflict of interest

WAA, CJVH, NM \& EWZ have nothing to disclose.

Financial support

This study was supported by grants from the National Research Foundation and the South African Thoracic Society.

\section{Abstract and keywords}

Background: Asthmatic children on corticosteroids can develop hypothalamic-pituitary-adrenal axis suppression (HPAS). Single nucleotide polymorphisms (SNPs) rs242941 and rs1876828 of the corticotrophinreleasing hormone receptor 1 (CRHR1) genewere associated with lower stimulated cortisol (F) levels, whereas rs41423247 of the glucocorticoid receptor (NR3C1) genewas associated with higher basal F levels. The objective of the current study was to confirmwhether these three SNPs are associated with HPAS in asthmatic children.

Methods: DNA was extracted from saliva obtained from 95asthmatic children, who had previously undergone basal F and metyrapone testing. Thirty-six children were classified as suppressed. Non-suppressed children were sub-classified according to their post-metyrapone ACTH (PMTP ACTH)level into a middle (106-319 $\mathrm{pg} / \mathrm{ml})$ and a high $(>319 \mathrm{pg} / \mathrm{ml})$ ACTH response group. TaqMan ${ }^{\circledR}$ polymerase chain reaction assays were utilized.

Results: Only rs41423247 was inversely associated with HPAS (OR $=0.27$ [95\% CI 0.06-0.90]). Its GC genotype was inversely associated with HPAS $(\log$ odds $=-1.28, \mathrm{p}=0.021)$. [?]PMTP ACTH was associated with $\mathrm{CC}$ (effect size $=10.85, \mathrm{p}=0.005$ ) and $\mathrm{GC}$ genotypes (effect size $=4.06, \mathrm{p}=0.023$ ). The $\mathrm{C}$ allele is inherited as a dominant trait (effect size $=-1.31(95 \% \mathrm{CI}-2.39--0.33 ; \mathrm{p}=0.012)$. In the high ACTH response group, both genotypes affected the PMTP ACTH (effect sizes 1.41 and 15.46; p-values 0.023 and $<2 \times 10^{-26}$ for GC and CC respectively).

Conclusions: TheC allele of rs41423247was found to be protective against HPAS. CC genotype is associated with the highest PMTPACTH response. 
Key words: Asthma, hypothalamus, pituitary, adrenal, polymorphism, receptors, glucocorticoids, steroids/adverse events, adrenal insufficiency, pituitary-adrenal-function tests

\section{Main text}

\section{Key Messages}

Rs41423247 (G/C) of the NR3C1 gene was found to be inversely associated with hypothalamic-pituitaryadrenal axis suppression (HPAS) in asthmatic children on steroids. The CC genotype is associated with the highest ACTH levels. If confirmed, the CC genotype could well be a marker of HPAS protection, thereby allowing for personalized treatment decisions to be made in asthma care.

\section{BACKGROUND}

It has been shown that $16.3 \%$ of asthmatic children treated with inhaled corticosteroids (ICS) and nasal steroids (NS) in Cape Town, South Africa, can develop hypothalamic-pituitary-adrenal axis suppression (HPAS) when assessed with the metyrapone(MTP) test. ${ }^{1-2}$ If partial forms of suppression are included, even two-thirds of children may be affected. A higher body mass index (BMI) was found to be protective against HPAS. Unfortunately suitable screening tests for HPAS are not available. ${ }^{3-4}$ The only viable alternative thus would be to identify gene variants, which would help to predict which children are either prone or resistant to developing HPAS. In Greek asthmatic childrenon inhaled corticosteroids, homozygotes for the single nucleotide polymorphisms (SNPs) rs242941 (TT) and rs1876828 (AA) of the corticotrophin-releasing hormone receptor 1 (CRHR1) gene were associated with lower stimulated cortisol (F) levels when tested with the low dose adrenocorticotropin $(\mathrm{ACTH})$ stimulation test $\left(0.5 \mu \mathrm{g} / 1.73 \mathrm{~m}^{2}\right)$. Heterozygotes $(\mathrm{GC})$ for rs41423247 ( $\mathrm{Bcl} l$ restriction length polymorphism) of the glucocorticoid receptor (NR3C1) gene,on the other hand,were found to have higher basal $\mathrm{F}$ levels. ${ }^{5}$ In the quest for universally applicable predictors of HPAS in asthmatic children on corticosteroids, the findings of the Greek study needed to be confirmed by a study, utilizing the gold standard metyrapone test, to determine whether the SNPs rs242941 and rs1876828 of the CRHR1, and rs41423247 of the NR3C1 gene are associated with HPAS in asthmatic school children on corticosteroids.

\section{METHODS}

\subsection{Participants}

Asthmatic children, 5-18 years old, treated with ICS and NS at the Lung Institute, Tygerberg and Red Cross Children's Hospitals in Cape Town, South Africa, whose hypothalamic-pituitary-adrenal axis (HPA) was previously assessed with a morning basal serum $\mathrm{F}$ and MTP testing,were re-recruited. ${ }^{1-2} \mathrm{HPAS}$ was diagnosed, if $\mathrm{F}<83 \mathrm{nmol} / \mathrm{l}$ or the post-MTP (PMTP) ACTH $<106 \mathrm{pg} / \mathrm{ml}(23.5 \mathrm{pmol} / \mathrm{l}), 11$-deoxycortisol $(11 \mathrm{DOC})<208 \mathrm{nmol} / \mathrm{l}$ and $11 \mathrm{DOC}+\mathrm{C}<400 \mathrm{nmol} / \mathrm{l}$.

\subsection{Study design and methodology}

A cross-sectional study was performed. Height, weight, sex and age were recorded as measured previously. The BMI z-score (Centre of Disease Control) was computed. Salivary samples were collected with an Oragene DNA collection kit (OG-500). Samples were stored at $-20^{\circ}$ C. Once all the samples were collected, DNA was extracted. Genotyping for rs242941, rs1876828 and rs41423247 was performed by using TaqMan ${ }^{\circledR}$ polymerase chain reaction (PCR) assays.Ethical approval was granted by the ethics committees of both Stellenbosch University and the University of Cape Town. The study conformed to the standards of the Declaration of Helsinki. All participants and their parents gave their informed consent prior to inclusion of the study.

\subsection{Statistical analysis and sample size considerations}

\subsubsection{Sample size}

In the previous study ${ }^{1} 30$ patients had hypocortisolaemia or HPAS. The cross-sectional design allowed for an equal number of patients to be analysed across the full spectrum of post-MTP responses i.e. low, midrange and high (30 subjects each). The ACTH mean and standard deviation (SD) were calculated (ACTH 
mean $=330 \mathrm{pg} / \mathrm{ml}[73.3 \mathrm{pmol} / \mathrm{l}], \mathrm{SD}=280 \mathrm{pg} / \mathrm{ml}[62.2 \mathrm{pmol} / \mathrm{l}])$ from the previous data. The proportional distribution of the genetic subgroups was derived from the paper of Tsartsali et al, table $4.7 \cdot{ }^{5}$ Power analysis with a sample size of 90 was done across the three ACTH groups. Significance level was taken as 0.05. A one-way analysis of variance test (ANOVA)was considered for the power analysis. The following mean values were specified under the alternative hypothesis: group 1 (low range) 230pg/ml (51.1 pmol/l), group 2 (midrange) $330 \mathrm{pg} / \mathrm{ml}(73.3 \mathrm{pmol} / \mathrm{l})$, group 3 (high range) $430 \mathrm{pg} / \mathrm{ml}(95.5 \mathrm{pmol} / \mathrm{l})$. This gives a $100 \mathrm{ACTH}$ units difference between two adjacent groups. This is a relative difference of $36 \%$ of the SD. $[(100 / 280)=0.36]$ which is a conservative expected effect size. Even for unbalanced groups such as n1=24, n2=35 and n3=40, the power will be $81 \%$. Thus the power is good if the sample size distribution across the genetic subgroups is moderately unbalanced. Power is improved by square root transformations of ACTH to stabilise the within group variances.

\subsubsection{Statistical analysis}

An online statistical tool (https://ihg.helmholtz-muenchen.de/cgi-bin/hw/hwa1.pl) and the R statistical packagewere used. Fisher's Exact and Pearson's Chi-squaretestswere conducted to test for statistical difference of minor allele counts. TheHardyWeinberg package version 1.6.3 installed in RStudio version 3.5.1 was used to assess whether the SNPs were inHardy-Weinberg equilibrium. To test for significance at SNP and genotype level, the Wald's test in multinom() function from thennet package in R was utilized. PMTP ACTH data were square root transformed and a one-way ANOVA performed. The Wilcoxon test was used for pairwise multiple comparisons of differences in mean [?]PMTP ACTH per SNP. Linear analysis for BMI z-score, [?]PMTP ACTH and binomial analysis for HPAS were conducted with the $\operatorname{glm}()$ function in R. The best genetic model for rs 41423247 was selected on the basis of the lowest significant Akaike information criterion. Significance level for all tests was taken as 0.05 .

\section{RESULTS}

A total of 96 patients (94 from previous studies ${ }^{1,2}$ and two newpatients) were recruited. One child had to be excluded, becauseof a discrepancy between the basal F level and the MTP test. The demographics, therapy and HPAS status of the 95 enrolled patients arelisted (table 1). Only one child was on oral prednisone at the time of testing. According to the basal $\mathrm{F}$ and the PMTP ACTH response, 35 children were classified in asuppressed ( $\mathrm{F}<83 \mathrm{nmol} / \mathrm{l}$ or ACTH $<106 \mathrm{pg} / \mathrm{ml}[23.5 \mathrm{pmol} / \mathrm{l}]$ ), 29 in a middle (ACTH 106-319 pg/ml [23.5-70.8 pmol/l] $)$ and 31 in a high $(\mathrm{ACTH}>319 \mathrm{pg} / \mathrm{ml}[70.8 \mathrm{pmol} / \mathrm{l}])$ ACTH response group.

All three SNPs were in Hardy-Weinberg equilibrium (rs242941A/C [suppressed ACTH response group $\mathrm{p}=0.830$;middle/high ACTH response group $\mathrm{p}=0.580$ ], rs1876828 A/T [suppressed ACTH response group $\mathrm{p}=0.791$;middle/high ACTH response group $\mathrm{p}=0.481$ ] and $\mathrm{rs} 41423247 \mathrm{G} / \mathrm{C}$ [suppressed ACTH response group $\mathrm{p}=0.445$; middle/high ACTH response group; $\mathrm{p}=0.948]$ ).

The rs41423247 (G/C) SNP was inversely associated with HPAS (OR $=0.27$ [95\% CI 0.06-0.90]). Both rs242941 (A/C) and rs1876828 (C/T) were not associated with HPAS, their OR being 0.99 (95\% CI 0.432.27 ) and 0.54 (95\% CI 0.05-3.48) respectively. Similarly, only the rs41423247 GC and GC+CC genotypes were inversely associated with the suppressed ACTH response group $(\mathrm{OR}=0.310$ [95\% CI: 0.137-0.920] and $\mathrm{OR}=0.296[95 \%$ CI: $0.1116-0.756])$. The homozygous CC genotype just missed statistical significance (OR $=0.101$ [95\% CI: 0.005-1.908], $\mathrm{p}=0.041)$. The mean [?]PMTP ACTH of the CC genotype was significantly higher $(\mathrm{p}=0.002)$ than for the GC and GG genotypes (fig 1$)$. The respective means and their 95\% CIs were 22.59 (16.18-29.00), 16.00 (13.00-19.00) and 11.82 (10.11-13.63). These correspond to real ACTH mean levels of $553.0 \mathrm{pg} / \mathrm{ml}(122.9 \mathrm{pmol} / \mathrm{l})$ for the $\mathrm{CC}, 331.0 \mathrm{pg} / \mathrm{ml}(73.6 \mathrm{pmol} / \mathrm{l})$ for the GC and $187.5 \mathrm{pg} / \mathrm{ml}(41.7$ $\mathrm{pmol} / \mathrm{l})$ for the GG genotype.

The frequency of the guanosine $(\mathrm{G})$ allele (the major allele) of rs41423247 was $77 \%$, while the frequency of the cytidine (C)allele (the minor allele) was $23 \%$. The genotype frequencies for GG, GC and CC were 60 , 34 and $6 \%$ respectively.

BMI was associated with the CC genotype (table 2) while the heterozygous GC was associated with HPAS, 
independently of BMI (table 3). Both the homozygous CC and the heterozygous GC genotypes were associated with [?]PMTP ACTH with CC having a significant larger impact than GC (table 4). The observed ACTH effect was independent of age, sex, height and weight (and hence of BMI). The higher the ACTH response, the greater and more significant the genotype (CC) effect (table 5).

After correcting for age, sex, height and weight, both the additive and the dominant genetic models were the best fit to describe the protective effect of the $\mathrm{C}$ alleleon HPAS. The effect size for the additive model was $-1.30(-2.32--0.42 ; \mathrm{p}=0.007)$ and for the dominant model, the effect size was -1.31 (95\% CI $-2.39--0.33$; $\mathrm{p}=0.012$ ). Similarly, the effect of the C allele on [?]PMTP ACTH is best described by an additive (effect size $=4.42[95 \%$ CI $1.77-7.07 ; \mathrm{p}=0.002])$ and a dominant model $($ effect size $=4.79[95 \%$ CI $1.54-8.04 ; \mathrm{p}$ $=0.005)$.

\section{DISCUSSION}

The SNP rs41423247 (GC) of theNR3C1 gene was found to be protective against HPAS, while no association with HPAS was found with rs242941 and rs1876828 of the CRHR1 gene. In contrast, in Greek asthmatic childrenbasal or stimulated F levels were differentfor all three SNPs. ${ }^{5}$ Thediscrepancy in the findings between results of the two studies can be explained by the use of different adrenal function tests. In the Greek study the low dose ACTH stimulation test (not the gold standard) was used without defining definitive cut-offs ${ }^{3,6}$ for basal and stimulated $\mathrm{F}$ levels. Relying on statistical differences of these levels vis-a-vis their respective genotypes could have led to erroneous conclusions. Furthermore, serum F is a very crude test, which is influenced by many variables ${ }^{3}$ e.g. by Circadian rhythm. There is no record in Tsatsali et al's paper whether the basal F levels were taken in the early morning (which is essential). The MTP test, utilized in this study, is a gold standard adrenal function test with clearly defined criteria for HPAS. Analyses based on this test can be expected to produce valid results. ${ }^{3}$

In a recently published genome-wide association study (GWAS) investigating susceptibility to HPAS in asthmatic children, screening was not performed for rs41423247 (GC). Instead rs591118, an intronic variant of the PDGFD gene, was significantly associated with HPAS. This particular SNP was not included in the current study, because the study was already completed when the paper reporting rs591118 was published.

In the current study, CC of rs41423247 is associated with higher ACTH levels when compared to theGCand GG genotypes. In adults with depression on the other hand, a dexamethasone/corticotropin-releasing hormone $(\mathrm{CRH})$ test revealed that a poor response to anti-depressive therapy was associated with marginally lower median peak ACTH levels in patients with the CC genotype. ${ }^{8}$ The results of this study could however have been confounded by the use of a variable dose of triiodothyronine given to some patients, which could have inducedunrecognised adrenal insufficiency in individuals at risk. ${ }^{9}$ Tsartsali et al ${ }^{5}$ and others ${ }^{10}$ reported that the GC genotype was associated with a significantly higher basal F level than the CC genotype. The GG genotype converselywas associated with lower F levels after a dexamethasone suppression test in Dutch elderlyindividuals. ${ }^{11}$ The authors interpreted this as "hypersensitivity" to glucocorticoids. However, on reanalysis of their paper, CC is associated with a significantly higher F level post-dexamethasone, suggesting glucocorticoid resistanceof the CC genotype.

Both the HPAS-protective effect and the ACTH response seem to be inherited in an additive and dominant fashion. A similar phenotype is therefore expected withthe heterozygous GCand homozygous CCgenotype, except that the phenotypic effect of the latter should be more pronounced. Although the overall sample size was probably adequate, the low minor allele frequency of $23 \%$ (compared to $38 \%$ in Europe ${ }^{12}$ ) and the low CC genotype frequency of $6 \%$ (compared to $40 \%$ in Greek children), limit the interpretation of the study. This resulted in overlapping CIs of the GC and CC genotypesand an incalculable lower bound of the CC CI.However, the additive genetic effectaccounted for a huge effect size and a highly significant $\mathrm{p}$-value $(<2 \mathrm{x}$ $\left.10^{-16}\right)$, which even far exceeds the required significance threshold for a GWAS $\left(5 \times 10^{-8}\right) \cdot{ }^{13}$ Hence, pending confirmation in a larger study, the most suitable marker for HPAS protection would still be rs41423247(CC) of theNR3C1 gene.

The biochemical phenotype attributed to both CC and GC genotypes ofrs41423247is akin to the one de- 
scribed in the syndrome of primary generalized glucocorticoid resistance (PGGR) ${ }^{14-16}$ In this syndrome there is dysregulation of $\mathrm{F}$ feedback at hypothalamic and pituitary level, resulting in elevated ACTH and possibly $\mathrm{F}$ levels. In the current study, early morning basal $\mathrm{F}$ levels of the children with rs41423247were not elevated (results not shown). Clinical features of this syndrome e.g. hypertension, hirsutism or premature pubarche,were not detected.Hence, the biochemical phenotype of rs41423247(GC and CC) couldrepresent tissue-specific glucocorticoid resistance. ${ }^{16}$ More likely, it isjust a common variant in the population (40\% in our sample)presenting with reduced glucocorticoid sensitivity. ${ }^{16}$

PGGR is associated with 26 mutations ${ }^{16}$ and 8 pathogenic SNPS ${ }^{17}$ in the exome of NR3C1 at 5 q31.3, while rs41423247falls within the intronic regulatory region of the gene,${ }^{12}$ confirmed independently by variant browser analysis(result not shown). Mechanistically, impaired promoter function would lead to impaired DNA transcription, RNA translation and protein production.

In a recently published study on asthma children in Turkey, the $\mathrm{FEV}_{1}$ ofchildren with the GG genotype improved more after a high dose of ICS than children with the CG+CC genotype. ${ }^{18}$ In the current study, three of five children with the CC genotype had a suboptimal $\mathrm{FEV}_{1}$ (result not shown). Unfortunately the number is too small to draw any valid conclusions from it.

In the same study population, it was previously shown that, as the BMI z-score rises, the ACTH level rises. ${ }^{1}$ In the current study, an association between CC genotypeand BMI z-score could be demonstrated. No association of genotype was found with overweight or obesity (results not shown). In Dutch elderly the GG genotype was associated with a lower BMI ${ }^{11}$, in line with the current study. However, others have found the opposite. ${ }^{19}$ Thehigher BMI z-score associated with rs41423247is probably mediated through periodically elevated F levels. However, as shown, the BMI z-score does not confound the SNP effect on the ACTH level.

As findings in Greek and South African children (and possibly Turkish children and Dutch adults) are similar, it is likely that the results of this study are generalizable across all populations and ages. Pathophysiological and molecular explanations of the observed phenotype should also be equally applicable to all humans. However, inadvertentlythe study islimited by the small sample of children with the CC genotype. Hence, alarger study should be performed to confirm the finding. In addition, a "proof of concept" study (screening asthmatic children for rs41423247 (CC), and when positive, testing them with the MTP testto confirm the phenotype)should be done. If confirmed, rs41423247 (CC), as a marker of HPAS protection, should be screened for in asthmatic children on glucocorticoids. This would allow clinicians to choose which children can be safely treated with higher doses of glucocorticoids - afirst step towards personalized medicine in asthma therapy.

In conclusion, rs41423247(GC) of theNR3C1 gene was found to be protective against HPAS. The CC genotype was associated with the highest ACTH levels. TheC allele is inherited as an additive and dominant trait. The GCgenotype was independently associated with BMI z-score. If confirmed by alarger and a "proof of concept" study,rs41423247 (CC) could well be a marker of HPAS protection, thereby allowing for personalized treatment decisions to be madein asthma care.

\section{ACKNOWLEDGEMENTS}

We are grateful to Carl Lombard from the Medical Research Council for calculating the sample size. Sisters Poggenpoel and Van Wyk are thanked for collecting the salivary samples of the patients. We express our gratitude toAlvera Vorsterfrom the Central Analytical Facility for the DNA extractions and genotyping of the participants. We thank Maia Lesosky from the School of Public Health, University of Cape Town, for statistical advice. For their advice on genetic modelling we are indebted to Heather Cordell from the International Centre for Life, Newcastle University and Ahmed Rabie, Centre of Biotechnology of Sfax, Tunisia.

\section{REFERENCES}

1. Zollner EW, Lombard CJ, Galal U, Hough FS, Irusen EM, Weinberg E. Hypothalamic-pituitary-adrenal axis suppression in asthmatic school children. Pediatrics 2012; doi: 10.1542/peds.2012-1147. 
2. Zollner EW, Lombard C, Galal U, Hough S, Irusen E, Weinberg E. Hypothalamic-pituitary-adrenal axis suppression in asthmatic children on inhaled and nasal corticosteroids - more common than expected? J PediatrEndocrinolMetab 2011; 24 (7-8): 529-534.

3. Zollner EW. Hypothalamic-piuitary-adrenal axis suppression in asthmatic children on inhaled corticosteroids: Part 1. Which test should be used ?Pediatr Allergy Immunol 2007;18:401 - 9.

4. Zollner EW, Lombard CJ, Galal U, Hough FS, Irusen EM, Weinberg E. Screening for hypothalamicpituitary-adrenal axis suppression in asthmatic children remains problematic: a cross- sectional study. BMJ Open 2013; pii: e002935.doi: 10.1136/bmjopen-2013-002935.

5. Tsartsali L, Papadopoulos M, Lagona E, Papadimitriou A, Kanaka-Gantenbein C, Louizou E, Kastania A, Priftis KN, Chrousos G. Association of hypothalamic-pituitary-adrenal axis-related polymorphisms with stress in asthmatic children on inhaled corticosteroids. Neuroimmunomodulation 2012; 19: 88-95.

6. Zollner EW. Asthma treatment in children: A guide to screening for and management of hypothalamic-pituitary-adrenal axis suppression. $\quad$ S Afr Med J 2019; 109(5):306-309. DOI:10.7196/SAMJ.2019.v109i5.13932.

7. Hawcutt DB, Francis B, Carr DF et al. Susceptibility to corticosteroid-induced adrenal suppression: a genome-wide association study. Lancet Respir Med 2018;6: 442-450.

8. Brower JP, Appelhof BC, Van Rossum EFC et al. Prediction of treatment response by HPA-axis and glucocorticoid receptor polymorphisms in major depression. Psychoneuroendocrinology 2006; 31: 1154-1163.

9. Garber JR, Cobin RH, Gharib H et al for the American Association of Clinical Endocrinologists and American Thyroid Association Taskforce on Hypothyroidism in Adults. Thyroid, 2012; 22 (12): 12001235 .

10. DeRijk RH, Single nucleotide polymorphisms related to HPA axis reactivity. Neuroimmunomodulation 2009; 16: 340-352.

11. Huizenga NATM, Koper JW, De Lange P, Pols HAPP, Stolk RP, Burger H, Grobbee DE, Brinkmann AO, De Jong FH, Lamberts SWJ. A polymorphism in the glucocorticoid receptor gene may be associated with an increased sensitivity to glucocorticoids in vivo. J ClinEndocrinolMetab 1998; 83: 144-151.

12. National Library of Medicine. National Center for Biotechnology Information. dbSNP. Short Genetic Variations. Reference SNP (rs) Report. rs41423247. https://www.ncbi.nlm.nih.gov/snp/rs41423247\#frequency_tab. Accessed April 7, 2020.

13. Dudbridge F, Gusnanto A. Estimation of Significance Thresholds for Genomewide Association Scans. Genet Epidemiol 2008; 32: 227-234.

14. NCBI Resources. OMIM. https://omim.org/entry/615962. Accessed January 17, 2020.

15. Jimene-Panizo A, Perez P, Rojas AM et al. Nonc-canonical dimerization of the androgen receptor and other nuclear receptors: implications for human disease. Endocrine-Related Cancer 2019; 26: R479-R497.

16. Van Rossum EFC, Van den Akker ELT. Glucocorticoid Resistance. In: Ghizzoni L, Cappa M, Chrousos G, Loche S, Maghinie M (eds): Pediatric Adrenal Diseases. Endocr Dev. Basel: Karger; 2011; 20. $127-136 \mathrm{pp}$.

17. https://www-ncbi-nlm-nih-gov.ez.sun.ac.za/clinvar/?term=NR3C1\%5Bgene\%5D. Accessed May 11, 2020.

18. Keskin O, UlucaÜ, Birben E, Coșkun Y et al. Genetic associations of the response to inhaled corticosteroids in children during an asthma exacerbation. Pediatr Allergy Immunol 2016: 27: 507-513.

19. Manenschijn L, Van den Akker ELT, Lamberts SWJ, Van Rossum EFC. Clinical Features Associated with Glucocorticoid Receptor Polymorphisms. An Overview. Ann NY AcadSci 2009; 1179: 179-198.

\section{Hosted file}

HPAS intron publication_tables.docx available at https://authorea.com/users/323697/articles/ 452248-hypothalamic-pituitary-adrenal-axis-suppression-in-asthma-a-glucocorticoidreceptor-polymorphism-may-protect 


\section{Hosted file}

HPAS intron publication_figure.docx available at https://authorea.com/users/323697/articles/ 452248-hypothalamic-pituitary-adrenal-axis-suppression-in-asthma-a-glucocorticoidreceptor-polymorphism-may-protect 